\title{
Penerapan Prinsip Desain Garden City Pada Perancangan Central
}

\section{Business District}

\author{
Safitri Dewi Sufian ${ }^{1}$, Yohannes Firzal ${ }^{2}$, Mira Dharma Susilawati ${ }^{3}$ \\ Program Studi Arsitektur, Fakultas Teknik, Universitas Riau
}

\begin{abstract}
Abstrak
Dengan lokasinya yang strategis di bidang perdagangan, ekonomi, pariwisata dan industri internasional, Kota Batam harus menjadi daerah yang potensial untuk dikembangkan. Untuk alasan ini, kota ini ditargetkan menjadi kota industri dan perdagangan. Pengembangan area baru seperti Central Business District (CBD) adalah upaya untuk meningkatkan potensi ini. Central Business District Batam dipandang sebagai kawasan ekonomi multifungsi dengan fasilitas perumahan dan rekreasi yang didukung oleh lokasi di Batam Center. Prinsip-prinsip desain teori Garden City dapat diterapkan untuk area ini. Menurut teori, pengembangan kota dapat berorientasi lingkungan dan sosial dan mendukung keberlanjutan kota dan mengarah pada penciptaan kota hijau, terlepas dari pengembangan industri. Prinsip-prinsip Garden City dapat menjadi salah satu fondasi dalam mengembangkan potensi Kota Batam untuk menjadi kawasan yang ramah lingkungan secara ekonomi dan sosial, sambil tetap memperhatikan penataan kawasan hijau, jalan, dan tata ruang bangunan berdasarkan fungsi kegiatan. Fasilitas di Batam CBD dibagi menjadi beberapa zona seperti komersial, perumahan, kantor, dan rekreasi dengan penambahan ruang publik ke dalam desainnya. Selanjutnya, dengan menggunakan prinsip-prinsip desain Garden City, desain dapat membuatnya lebih mudah bagi pengguna untuk melakukan kegiatan dan tampak lebih berkembang dan terorganisir, sementara juga menyesuaikan diri dengan lingkungan dan sosial, untuk menarik perhatian investor di kota ini.
\end{abstract}

Kata Kunci : perancangan arsitektur, central business district, garden city, batam

\begin{abstract}
With its location in a strategic area of trade, economy, tourism and international industry, Batam City has to become a potential area to develop. For this reason, the city is targeted to be an industrial and trade city. The development of a new area such as the central business district (CBD) is an effort to increase this potential. Batam Central Business District is seen as a multifunctional economic area with residential and recreational facilities that is support by location in Batam Center. The design principles of the Garden City theory can be applied to this area. According to the theory, city development can environmentally and socially be oriented and supports the sustainability of a city and leads to the creation of a green city, apart from industrial development. The Garden City principles can be one of the foundations in developing Batam City's potential to become an economically and socially environmentally friendly region, while still paying attention
\end{abstract}


Penerapan Prinsip Desain Garden City Pada Perancangan Central Business District

to the arrangement of green areas, roads and building layouts based on the function of activities. The facilities in Batam CBD are divided into several zones such as commercial, residential, office, and recreation with the addition of public space into its design. Furthermore, by using the Garden City design principles, the design can make it easier for users to carry out activities and appear to be more developed and organized, while also adjusting to the environment and social, to attract the attention of investors in this city.

Keywords : architecture design, central business district, garden city, batam

\section{Pendahuluan}

Berada pada kawasan strategis perdagangan, perekonomian, pariwisata, dan industri internasional, Kota Batam merupakan daerah yang sangat potensial untuk lebih dikembangkan, serta menjadi kota industri dan perdagangan atau Batam Free Trade Zone (Permen No.46, 2007).

Dengan potensi kebebasan kawasan FTZ yang didukung dengan infrastruktur, pengembangan kawasan baru berupa Batam Central Business District (CBD) merupakan salah satu upaya untuk meningkatkan potensi tersebut. Batam CBD merupakan pusat perekonomian multifungsi (mixed use) yang dapat menampung beberapa fungsi kegiatan di dalamnya, seperti kegiatan ekonomi, sosial dan budaya. Selain itu, pada Batam CBD juga dapat mewadahi area hunian (residensial) serta sarana rekreasi dan open space.

Prinsip desain the Garden City dapat diterapkan pada perancangan kawasan CBD. Prinsip pembangunan kota berorientasi berwawasan lingkungan dan sosial serta mendukung keberlanjutan, sehingga pembangunan suatu kota tidak hanya berorientasi pada pengembangan industri saja, namun juga mengarah kepada suasana kawasan hijau. Prinsip desain the Garden City dipandang tepat untuk digunakan pada perancangan kota baru dengan ukuran kecil, terencana, dan dikelilingi oleh permanent belt.
Howard (1898) mengemukakan konsep the Garden City melalui prinsip perancangan; The advatages of the most energetic and active town life, with all the beauty and delight of the country, maybe secured in pefect combination. Hal ini menyiratkan bahwa merancang suatu kawasan menjadi kota yang hidup, energi dan aktif, dihiasi keindahan dan suasana desa atau pinggiran kota. Prinsip tersebut kemudian diadaptasi oleh Ni'mah dan Sudaryono (2009) menjadi prinsip kota baru sebagai kota mandiri, pola penggunaan (penataan) lahan, dan keseimbangan komunitas (pusat kegiatan). Ross dan Cabannes (2015) mengatakan bahwa setiap kota atau lingkungan dapat dianggap sebagai kota taman jika memiliki prinsip berhubungan dengan alam.

Berdasarkan prinsip desain the Garden City, terdapat 5 (lima) prinsip utama dalam perancangan yaitu: central place (pusat kegiatan), radial avenue (jalur sirkulasi), tata guna lahan, green belt (area penghijauan), dan integrasi antar fungsi dan aktivitas.

Beberapa aplikasi dari suatu kota atau kawasan yang menerapkan prinsip desain the Garden City dapat dikenali dari taman dan ruang hijau menjadi area yang sangat penting secara teknis. The Garden City membagi kawasan menjadi beberapa zona berdasarkan fungsi dan aktivitas yang dihubungkan oleh jalur sirkulasi, bangunan publik berdekatan dengan taman pusat kota, pola kota tidak harus melingkar dan radial, cenderung mengikuti pola jalur sirkulasi, taman yang tersebar, Crystal Palace yang 
merupakan area komersial, grand Avenue sebagai jalur arteri utama pada Garden City memisahkan zona - zona, terutama area residental dan industri. Prinsip desain lalu lintas ditujukan untuk membatasi jumlah pengguna kendaraan dan mendukung pejalan kaki, green belt yang mengelilingi kota, serta open space untuk umum yang dikelola dan disewakan kepada warga.

Perancangan Batam CBD merupakan upaya untuk meningkatkan potensi kota dengan menerapkan prinsip desain the Garden City ke dalam proses perancangannya, baik itu dari segi desain maupun fungsi, namun tetap memperhatikan penataan area hijau, jalan, dan tata letak bangunan berdasarkan fungsi kegiatan, sehingga menjadi kawasan yang ramah lingkungan dan sosial. Rencana fasilitasfasilitas dapat dikelompokkan menjadi beberapa zona yaitu; komersil, hunian, kantor, dan rekreasi, serta public space. Selain itu, dengan prinsip desain the Garden City juga dapat memudahkan pengguna untuk melakukan aktivitas dan terkesan maju, tertata lebih baik, serta tetap dapat menyesuaikan dengan lingkungan dan sosial. Sehingga diharapkan dapat menarik perhatian investor dan perusahan untuk berinvestasi dan membangun di Kota Batam.

Permasalahan yang akan dihadapi dalam perancangan Batam CBD ini adalah:

a. Bagaimana menentukan fasilitas yang sesuai dengan kegiatan yang ada pada Batam Central Business District?

b. Bagaimana cara menerapkan prinsip desain the Garden City ke dalam perancangan Batam Central Business District?

c. Bagaimana merumuskan konsep ke dalam perancangan Batam Central Business District?

Berdasarkan permasalahan tersebut, maka didapatlah tujuan sebagai berikut. a. Menentukan fasilitas yang sesuai dengan kegiatan yang ada pada Batam Central Business District;

b. Menerapkan prinsip desain the Garden City ke dalam perancangan Batam Central Business District;

c. Merumuskan konsep ke dalam perancangan Batam Central Business District.

\section{Metodologi}

\section{Strategi Perancangan}

Dalam perancangan Batam CBD diperlukan landasan konseptual yang melandasi perancangan fisik kawasan. Strategi perancangan yang dilakukan yaitu diawali dengan studi literatur. Dilakukan dengan penelusuran instansi terkait sehingga proses dan hasil perancangan mengacu pada peraturan perundangan yang berlaku di Indonesia, khususnya di Kota Batam.

Strategi berikutnya melalui observasi lapangan untuk pengambilan data dengan mengamati secara langsung. Aplikasi 5 (lima) prinsip utama yaitu; central place (pusat kegiatan), radial avenue (jalur sirkulasi), tata guna lahan, green belt (area penghijauan), dan integrasi antar fungsi dan aktivitas. Kemudian dilanjutkan dengan analisis kawasan dan wilayah yang merupakan proses untuk mengidentifikasi fungsi, menganalisis, memetakan, mengapresiasi konteks lingkungan dan nilai lokal kawasan dan wilayah sekitarnya. Analisis kawasan dikelompokkna menjadi dua yaitu; analisis fisik kawasan dan analisis nonfisik kawasan.

Skematis solusi desain merupakan strategi perancangan selanjutnya yang menyatukan hasil analisis kawasan dan prinsip desain the Garden City sehingga ditemukan pemecahan permasalahan arsitektural dan dapat sebagai 
Penerapan Prinsip Desain Garden City Pada Perancangan Central Business District

alternatif-alternatif solusi desain. Kemudian diakhir dengan perumusan konsep rancangan sebagai ide yang timbul dari hasil kesimpulan analisis melalui hasil pertimbangan skematis solusi desain sehingga dapat menjadi acuan dasar dalam proses perancangan.

\section{Metode Pengumpulan Data}

Data dikumpulkan dari informasi primer dan sekunder. Metode pengumpulan dapat dijelaskan sebagai berikut; data primer didapat melalui pengamatan terhadap obyek secara langsung seperti survey lapangan (obsevasi) dan dokumentasi. Sedangkan data sekunder diperoleh dari literatur atau data yang bersumber secara tak langsung. Pencarian data sekunder ini juga meliputi studi literatur dan studi banding.

\section{Lokasi Perancangan}

Lokasi perancangan berada di Kota Batam, area Simpang Jam, Kecamatan Batam Kota.

$$
\begin{array}{ll}
\text { Luas Lahan } & : \pm 33 \mathrm{Ha} \\
\text { KDB } & : 60 \% \mathrm{~s} / \mathrm{d} 70 \%
\end{array}
$$

Kontur : Berkontur

\section{Kondisi Eksisting : Lahan kosong}

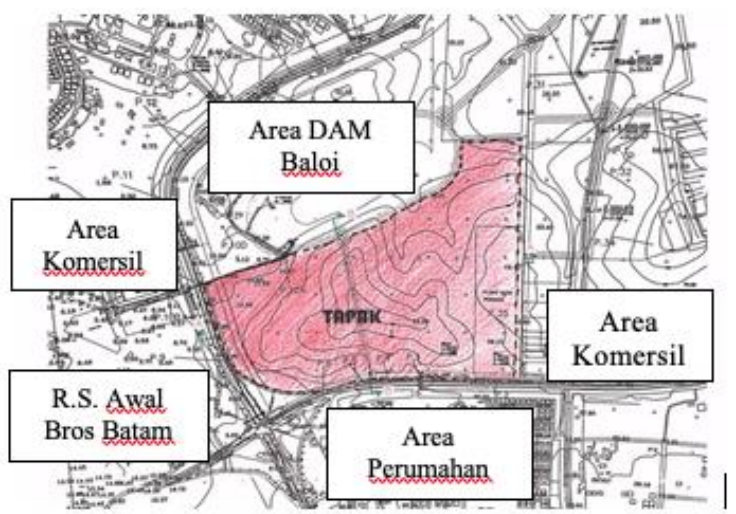

Gambar 1. Lokasi Tapak Kawasan

\section{Hasil dan Pembahasan}

Hasil dan pembahasan perancangan kawasan CBD dipaparkan berdasarkan penerapan prinsip desain the Garden City. Konsep perancangan City in a Garden mencerminkan sebuah kawasan yang memiliki beberapa fungsi namun tetap memperhatikan lingkungannya. Hal ini sesuai dengan peruntukan kawasan Batam CBD sebagai kawasan perekonomian dengan beberapa fungsi sehingga menyerupai sebuah kota kecil mandir.

Central place (pusat kegiatan), sesuai dengan karakteristik dari the Garden City, lahan terbagi menjadi beberapa zona berdasarkan fungsi dan aktivitas yang dihubungkan oleh jalur sirkulasi. Pembagian zona kawasan berdasarkan fungsi, yaitu komersil, hunian, perkantoran, dan taman. Zonasi ini dipisahkan oleh jalur sirkulasi.

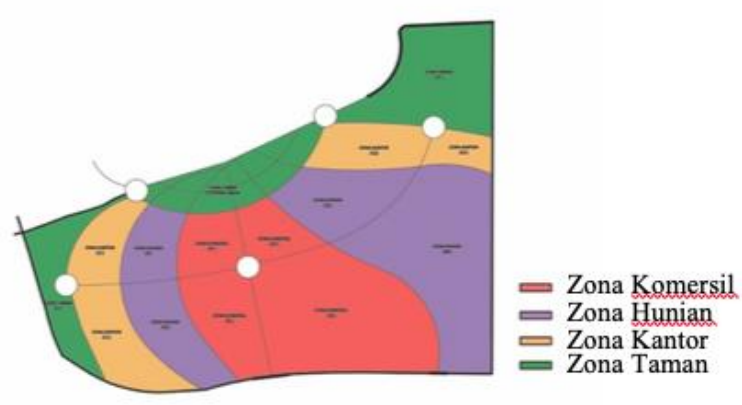

Gambar 2. Zonasi Kawasan

Radial avenue (jalur sirkulasi), zona-zona dihubungkan oleh jalur sirkulasi, dan pola kota menurut prinsip desain ini tidak lah harus melingkar atau radial. Namun pola penataan Kawasan cenderung mengikuti pola jalur sirkulasi. Dalam kasus Batam CBD, pola sirkulasi mengelilingi kawasan dan mengarah ke taman pusat. 


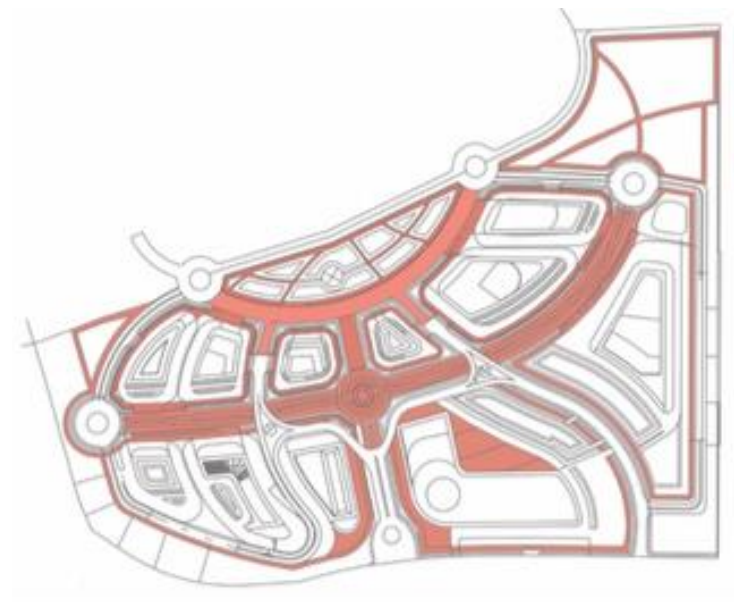

Gambar 3. Jalur Pedestrian pada Kawasan

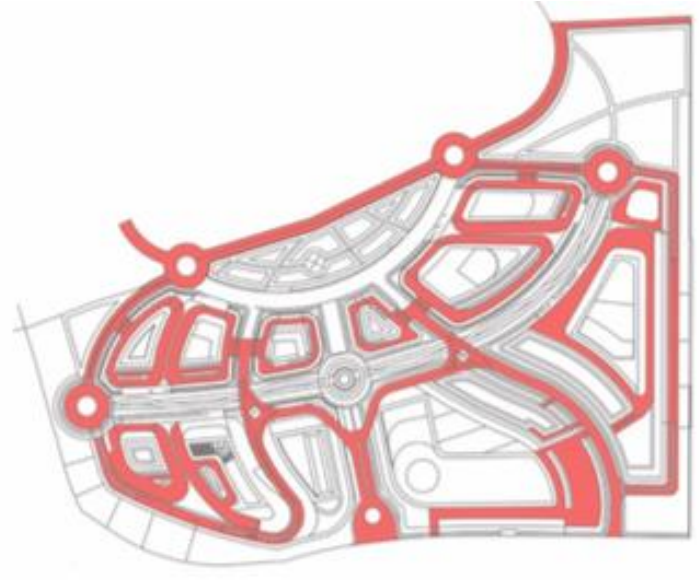

Gambar 4. Jalur Kendaraan pada Kawasan

Tata guna lahan, berdasarkan karakteristik prinsip desain the Garden City; bangunan publik berdekatan dengan taman pusat kota, Crystal Palace, grand avenue sebagai jalur arteri utama dengan meletakkan daerah daerah, taman dan ruang hijau sebagai area yang sangat penting, serta lebih mengutamakan pejalan kaki. Sebagai inti kawasan berupa open space (ruang terbuka publik) yang juga difungsikan sebagai jalur arteri utama kawasan.

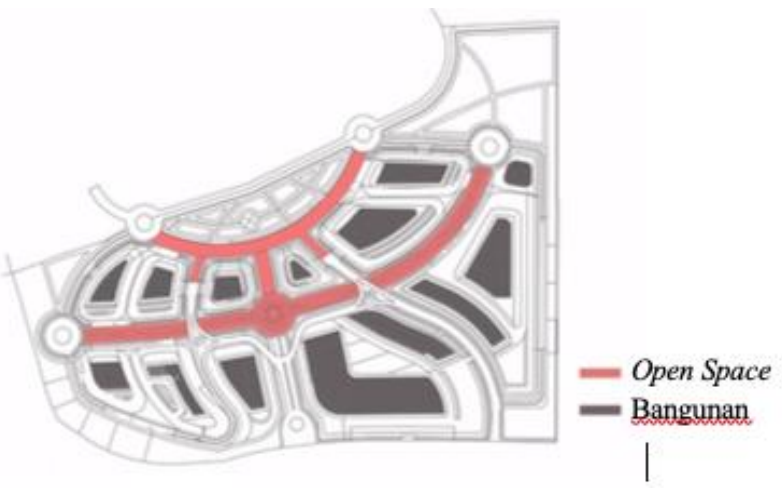

Gambar 5. Open Space sebagai jalur arteri utama kawasan

Green belt (area penghijauan), taman dan dominasi vegetasi menjadi penyatu (pengikat) Kawasan. Taman pusat berfungsi sebagai pusat pola kawasan. Hal ini sesuai dengan karakteristik prinsip the Garden City yaitu terdapat green belt yang mengelilingi kota, serta taman dan ruang hijau menjadi area pengikat kawasan. Lebih jauh, integrasi antar fungsi dan aktivitas, penghubung kawasan ini berupa jalur sirkulasi dan area hijau sekaligus juga sebagai pengikat kota.

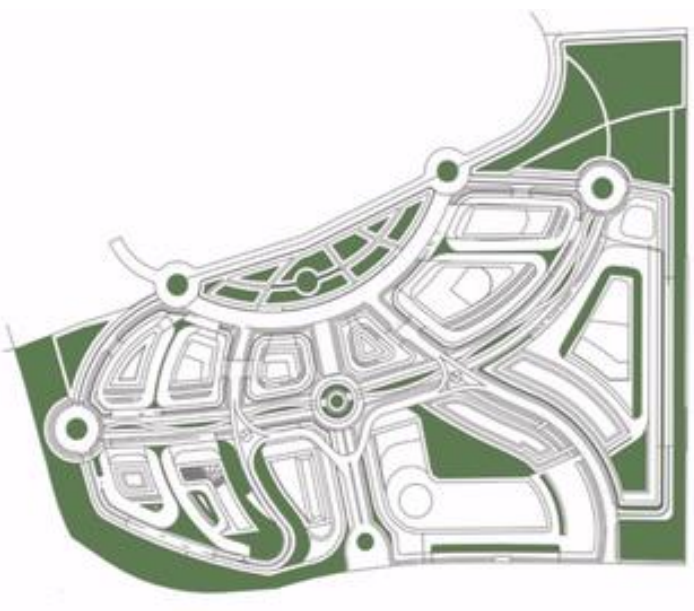

Gambar 6. Taman dan Area Hijau Kawasan

\section{Kesimpulan}

Perancangan kawasan Batam CBD dengan pendekatan prinsip desain the Garden City dapat disimpulkan bahwa: 
Penerapan Prinsip Desain Garden City Pada Perancangan Central Business District

1. Kawasan dirancang dengan berbagai fasilitas yang bertujuan sebagai suatu upaya dalam meningkatkan potensi Kota Batam;

2. Perancangan kawasan dengan pendekatan perancangan prinsip desain the Garden City agar menjadi kawasan bisnis yang ramah lingkungan dan sosial;

Adapun saran yang diperlukan untuk Batam CBD yaitu pengembangan Kawasan untuk lebih mempertimbangkan kesesuaian tata guna lahan, proses perawatan, dan pemeliharaan kawasan guna mempertahankan potensi kawasan. Pemahaman yang lebih mendalam terhadap tema dan fungsi harus lebih diperhatikan dalam perancangan.

\section{Daftar Pustaka}

Anwar, K. dan Yanti, N. (2014). Dinamika Pelaksanaan Kawasan Perdagangan Bebas dan Pelabuhan Bebas (Free Trade Zone) Batam. Jom FISIP. Online. Volume 1. No.2. (http://jom.unri.ac.id/index.php/JOMFSIP/arti cle/view/3229/3129, diakses 9 Mei 2018).

Howard, E. (1967). Garden Cities of Tomorrow, USA, The MIT Press, pp: 51-55, 75, 92-93, 96111, 139, 142, 144, 138-150, (reprinted and edited with a Preface by F. J. Osborn and an Introductory Essay by Lewis Mumford from the 1902 ed.). Sumber: http://www.sacredtexts.com (diakses: 18 Desember 2018).

Ni'mah, N. M. dan Sudaryono. (2009). Bentuk Implementasi Konsep Kota Taman Di Jepang: Konseptualisasi Dan Prinsip Perencanaan Dalam Uraian Sejarah. Jurnal Perencanaan Wilayah dan Kota. Online. Volume 20. No.01. Hal. (http://journals.itb.ac.id/index.php/jpwk/artic le/view/4168, diakses 28 Oktober 2018).

Philip R. dan Cabannes, Y. (2014). 21st Century Garden Cities of To-Morrow. A Manifesto. Hawthorn Press: United Kingdom.

Republik Indonesia. Peraturan Pemerintah Republik Indonesia No. 46 Tahun 2007 tentang Kawasan Perdagangan Bebas dan Pelabuhan Bebas Batam. 